\title{
MODOS HÍBRIDOS Y COMPLEJOS DE INFORMAR SOBRE COOPERACIÓN
}

\section{Hybrid and Complex Frames to Inform about Cooperation}

\section{Modos híbridos e complexos de informar sobre cooperação}

Giró, Xavier. Universidad Autónoma de Barcelona (España)

xavier.giro@uab.cat

Fecha de recibido: 1 de junio de 2016

Fecha de aceptado: 1 de julio de 2016

\section{RESUMEN}

El estudio de 112 reportajes sobre la cooperación internacional en distintos medios catalanes y españoles muestra que esta no es exclusiva dentro del denominado marco de la "ayuda y caridad" o de la "justicia y equidad", sino que a menudo se presenta de forma híbrida. Por otra parte, al completar el estudio con entrevistas a periodistas y cargos de la redacción de los medios estudiados, se deduce que el o los marcos resultantes están en función de un complejo engarce de variables: la acción cooperativa, la fuente-actor que la explica, la cultura social de la cooperación, la ideología del medio, la sección del medio en el que se publica y la ideología del redactor.

Palabras clave: periodismo, cooperación internacional, caridad, justicia.

\section{ABSTRACT}

The study of the coverage of the international cooperation in a set of 112 reports from different Spanish and Catalan media shows that it does not follow exclusively either the so-called "Aid and Charity" frame nor the "Justice and Equity" one, but very often both together. Furthermore, taking into account the interviews held with reporters and 
editors, it can be implied that the resulting frame is a function of a complex combinations of variables: the action itself, the source-actor explaining it, the social culture on cooperation, the medium's ideology, the section where it is published and the journalist's ideology.

Keywords: journalism, international cooperation, charity, justice.

\section{RESUMO}

O estudo da informação sobre a cooperação internacional é um conjunto de 112 reportagens em distintos meios catalães e espanholes mostra que não se dá de forma exclusiva dentro do denominado marco (frame) da "Ajuda e Caridade" ou dentro do marco da "Justiça e Equidade", senão que amiúde se apresenta de forma híbrida. Por outra parte, ao completar o estudo com entrevistas a jornalistas e cargos da redação dos meios estudados, se deduz que o ou os marcos resultantes estão em função de um complexo encaixe de variáveis: a ação cooperativa, a fonte-ator que a explica, a cultura social da cooperação, a ideologia do meio, a seção do meio onde publica-se e a ideologia do redator.

Palavras-chave: jornalismo, cooperação internacional, caridade, Justiça

\section{Introducción}

Presentamos el resultado final de un estudio sobre la cobertura de la cooperación internacional en medios de comunicación (dos canales de televisión, dos estaciones de radio, nueve periódicos y un portal web), motivado por la preocupación de comprobar que, a pesar de dar apoyo a la ayuda oficial al desarrollo, la ciudadanía catalana mostraba un conocimiento muy superficial de lo que es y de lo que supone el sistema internacional de ayuda y solidaridad, así como de los roles que tienen los agentes.

Desde esa preocupación, la federación de ONG para el desarrollo de Cataluña lanzó un proyecto para la creación de una red europea transregional de periodistas, comunicadores (encuadrados en ONG) e investigadores para impulsar la presencia regular de informaciones de calidad sobre los países empobrecidos y la cooperación internacional en los medios.

El proyecto, denominado "Red de periodistas y comunicadores/as para la cooperación y el desarrollo" logró la financiación de la Unión Europea (Proyecto núm. DCI-NSAPVD/2012/279-805) y liderado por la Federación catalana de ONG, tuvo como socios a la Red de Apoyo a la Cooperación (Resacoop) de Rhône Alpes (Francia) y a la Coordinadora de ONG del Piamonte (COP) (Italia).

Uno de los primeros pasos del proyecto consistió en establecer un diagnóstico sobre el discurso de los medios a propósito de la cooperación con los países del sur y este. El que presentamos es el resultado. 


\section{Marco teórico}

El marco teórico de la presente investigación se basa en el enfoque denominado análisis crítico de discurso (ACD) con una metodología de análisis textual y sociocognitivismo combinada con framing. El ACD se preocupa, en palabras de Teun Van Dijk (2009), por demostrar "cómo mediante el texto y el habla en un contexto social y político se promueve, reproduce y se combate el abuso de poder, la dominación y la desigualdad” (p. 23).

El discurso de los medios de comunicación condiciona la concepción de la cooperación que se forman sus audiencias, ya que informar consiste en exponer una narración que implica una toma de posición sobre los acontecimientos. A veces es explícita y otras es implícita, pero el estudio del lenguaje en su contexto permite traerla a la superficie. Analizar el discurso es "inevitablemente un proceso estructurado que, si se hace adecuadamente, ha de revelar las ideologías, los valores y las posiciones implícitas, mostrando así que el discurso es siempre una representación desde un cierto punto de vista" (Fowler, 1991, p. 209).

Entre las metodologías del ACD (Wodak y Meyer, 2001), hemos elegido una que combina herramientas de la lingüística crítica prestadas de Van Dijk (2001) y Sigfried Jäger (1999) (una aleación de análisis textual, pragmática y sociocognitivismo) y de la teoría y técnica conocida como framing (Goffman, 1974; Lakoff, 2004).

Establezcamos los conceptos. Las informaciones contienen ideas que se pueden sintetizar en forma de proposiciones y que transmiten valoraciones sobre los actores y sus acciones, de modo que en una misma información puede haber distintas proposiciones. Si una proposición resume el conjunto del significado de una pieza periodística, la llamaremos macroproposición. Puede ser que para resumir tal significado sean necesarias distintas macroproposiciones (Van Dijk, 1996a; 1996b; 1997).

Denominamos "pieza periodística" a cualquier unidad discursiva sin tener en cuenta su género periodístico y así evitamos la distinción formal entre informaciones y opiniones, lo cual presupondría, de manera errónea, que las informaciones no estarían cargadas de ideología.

Definidos los conceptos anteriores, se puede señalar que las macroproposiciones resumen una pieza periodística y el conjunto de macroproposiciones extraídas de las piezas de un medio componen lo que llamamos su matriz ideológica en un campo preciso durante un período determinado.

Las proposiciones pueden ser explícitas o implícitas. La identificación de las primeras no ofrece mayor problema; sin embargo, para extraer las implícitas, es necesario conocer el contexto en el que se despliega el discurso; de aquí que el ACD sea interdisciplinar, pues necesitamos saber qué modelos de cooperación existen para deducir lo que dicen los medios, más allá de lo afirmado literalmente. El estudio de Andrew Darnton y Martin Kirk (2011) (FF) proporciona esa base teórica suplementaria.

\section{Finding frames, valores y marcos}

La investigación Finding Frames (FF) (Darnton y Kirk, 2011) se generó tras la constatación de que la campaña Make Poverty History ("Hagamos que la pobreza forme parte del pasado"), realizada en 2005 por diversas organizaciones del Reino Unido, había fracasado en su objetivo de transmitir una nueva idea en ruptura con la tradición: la idea de que la cooperación era una cuestión de "justice, not charity" (justicia, no caridad). O sea, después de la campaña, 


\section{DISERTACIONES}

ESTUDIOS

Anuario electrónico de estudios en Comunicación Social

ISSN: $1856-9536$

Doi: dx.doi.org/10.12804/revistas.urosario.edu.co/disertaciones/a.4914

Volumen 10, Número 1 / Enero-junio 2017

Versión PDF para imprimir desde

http://revistas.urosario.edu.co/index.php/disertaciones

la cooperación seguía enmarcada dentro de la idea de caridad, en lo que viene a denominarse marco hegemónico, el tradicional. El marco no había cambiado y, a pesar de la campaña, continuaba su dominio ideológico.

¿Qué son los marcos? Para entenderse, los seres humanos usan "marcos interpretativos"; en breve, marcos.

En el lenguaje, por ejemplo, nuestro marco para una palabra no [solo] es el significado que le da el diccionario, sino también todas las otras cosas que sabemos, sentimos o hemos experimentado con relación a esa palabra. Cuando oímos una palabra en particular o nos encontramos en una situación específica, [...] se activan en nuestro cerebro. Esto es el frame - marco- para una palabra o acontecimiento (Darnton y Kirk, 2011, p. 7).

Se trata de una explicación de los marcos que podemos completar brevemente. Una palabra no solo trae asociado el significado del diccionario, sino que su significado efectivo viene dado por el uso que se haga de ella, como explicó Wittgenstein (1984) y el uso está determinado por el modelo mental de la situación de comunicación en el que se encuentran los participantes en el intercambio, es decir, el modelo mental opera como marco que da sentido a todos los elementos que lo componen.

El estudio FF parte del trabajo de George Lakoff (2004), quien distingue dos tipos de marcos: los profundos y los superficiales. Los profundos representan visiones globales del mundo y están conectados a sistemas de valores. Se trata de una definición equivalente a la de ideología en ACD: un conjunto de creencias compartidas por un grupo social sobre cómo es y cómo debe ser el mundo (Van Dijk, 1996; 1998). Es una definición que ya daba Stuart Hall (1996). Correlativamente, los marcos superficiales definidos por Lakoff serían fragmentos de conocimiento relacionados con una palabra o un término.

Los marcos profundos son estructuras de conocimiento que explican cómo funcionan las cosas y el mundo e incorporan los roles de los actores y sus guiones de actuación. Cada marco profundo es en sí mismo un producto ideológico - porque establece cómo es el mundo y cómo debería ser- $y$, si se les considera agrupados, conforman una ideología. Los marcos profundos son evocados, activados por marcos superficiales y, según los autores de FF (Darnton y Kirk, 2011), entre ellos hay marcos que fomentan la cooperación y la solidaridad, entendidas como justicia y equidad, y, en oposición a ellos, hay otros marcos que fomentan la ayuda y la caridad, desde una perspectiva asistencialista.

Los marcos superficiales se identifican por palabras que, aunque sean neutras en principio, situadas en su contexto activan un marco asistencial o un marco alternativo transformador. Veamos los marcos superficiales identificados, en línea con el estudio de FF, en relación con la cooperación y la solidaridad internacionales (Darnton y Kirk, 2011). Vamos a revisar siete contraposiciones alternativas.

En primer lugar, el marco de la caridad se refiere a la beneficencia en el más puro sentido asistencial. Enfatiza la diferencia entre los ricos que dan (a menudo, lo que les sobra) y los pobres que lo reciben de forma pasiva. Además de la misma palabra "caridad", entre los términos que componen este marco están "donación”, "donante”, "beneficiario", "víctima", "damnificado", "pobre" o "países pobres".

De modo alternativo se encuentra el marco de la justicia y la equidad, términos vinculados con los derechos de las personas, el empoderamiento y el apoyo mutuo. Enfatiza en el cambio de sistema a favor de una relación igualitaria y lo expresan con claridad las palabras: "política/políticas", "cambio social”, "transformación”, "justicia social”, "incidencia política”, "compromiso”, "socios", "colaboradores” y “(países) empobrecidos”. 


\section{DISERTACIONES}

ESTUDIOS

Anuario electrónico de estudios en Comunicación Social

ISSN: $1856-9536$

Doi: dx.doi.org/10.12804/revistas.urosario.edu.co/disertaciones/a.4914

Volumen 10, Número 1 / Enero-junio 2017

Versión PDF para imprimir desde

http://revistas.urosario.edu.co/index.php/disertaciones

Existe también el marco de las organizaciones caritativas o benéficas y, como marco alternativo a este, aparecen los movimientos sociales y las ONG comprometidas con la cooperación como justicia global y equidad.

La ayuda también es un marco tradicional. Esta es el objeto central de la cooperación entendida como transacción monetaria en la que quien tiene, considerado superior, da a quien no tiene, considerado como inferior. No se usa solo para emergencias, sino también cuando se habla de "ayuda al desarrollo". FF propone otro marco, que sitúa el énfasis en el apoyo mutuo, en las contrapartes locales, el establecimiento del partenariado y la interdependencia entre el Norte y el Sur (Darnton y Kirk, 2011).

El "desarrollo" es un término que entre profesionales puede ser bien entendido, pero entre profanos se comprende como una idea positiva del modelo de desarrollo del Norte que sería exportable al Sur. Genera la dicotomía entre "países desarrollados" (Occidente) y "subdesarrollados" o "en vías de desarrollo". Los conceptos de "crecimiento económico", "PIB" y "globalización económica" van asociados con este marco ya tradicional.

El marco alternativo correspondiente puede llamarse "bienestar, libertad, responsabilidad". De acuerdo con Amartya Sen (1999), se entendería como el desarrollo de las capacidades que deben tener las personas para hacer que sus derechos sean ejecutables efectivamente como libertades e, incluso, en línea con Giri, el desarrollo como responsabilidad, "porque el discurso de la libertad [...] continúa siendo incapaz de asumir el sufrimiento que el yo necesita para poder cumplir con su responsabilidad frente a los otros" (2005, p. 342, citado en Darnton y Kirk, 2011, p. 94).

Aún más alejado del término "desarrollo", en los últimos años ha emergido una visión de raíz andina conocida por la expresión aimara "suma qamaña", traducida como "vivir bien" o "buen vivir", mejor expresada por "convivir bien" como propone el lingüista y antropólogo Xavier Albó (2011). Las expresiones "convivir bien" o "buen vivir", que tienen la ventaja de aportar una visión ecológica, política y holística diferente, no solo superan la noción vehiculada por el concepto antiguo de desarrollo, sino también la menos antigua de "cambio social", como apuntan Chiara Sáez Baeza y Alejandro Barranquero (2014).

Este marco alternativo se evoca al hablar de las desigualdades y sus causas, al medir no solo la pobreza económica, al discurrir sobre los derechos políticos, sobre el ambiente; sobre desarrollo en sentido global y sobre el índice de desarrollo humano.

En cuanto al marco de la "corrupción", también es una cuestión de énfasis. No es que hablar de ella sea propio del marco tradicional, sino de que al tratar sobre el Sur, se suele hablar de países o Gobiernos corruptos, pero poco de Gobiernos o poderes corruptores del Norte o de la herencia de la corrupción colonial o neocolonial, de modo que la mayor responsabilidad se hace recaer sobre el Sur.

Hablar de la poca efectividad de la ayuda, ya sea por malversación o por ineficacia de los que la reciben, se ubica en la misma tendencia a cargar las responsabilidades en el Sur. Hablar del "mal o buen gobierno" también será propio del marco tradicional o del transformador, según dónde se ponga el acento. En el marco tradicional, el Gobierno es bueno si sirve a los intereses de Norte. Alternativamente, se puede hablar de buena o mala gestión del Gobierno en función de los efectos que tenga sobre la población del Sur (no en relación con los intereses del Norte), sea en el momento que sea y sin que suponga una generalización para todo el Sur.

La "comunicación" es otro marco tradicional, si se concibe como una relación unidireccional con el público. Se convierte en un sinónimo de márquetin, captación de fondos, colectas, donaciones, etc. En positivo, podría significar un diálogo que fomente la sensibilización y la participación entre ONG y sus asociados o la ciudadanía. 
Para finalizar, con el término "campañas para emergencias" ocurre algo similar, porque activa el marco de la beneficencia que debería ser únicamente puntual. En su lugar, el marco del "compromiso" y la "implicación" buscaría una comprensión afinada de los problemas del Sur y estaría enfocado hacia la acción, el voluntariado y el partenariado.

La tabla 1 condensa y contrapone los dos marcos:

Tabla 1. Los marcos de la cooperación

\begin{tabular}{|l|l|}
\hline \multicolumn{1}{|c|}{ Asistencial } & \multicolumn{1}{c|}{ Transformador } \\
\hline Caridad & Justicia y equidad \\
\hline Entidades benéficas & Movilización social, ONG \\
\hline Ayuda & Partenariado, apoyo mutuo \\
\hline Desarrollo & Bienestar, libertad, responsabilidad \\
\hline Corrupción & Buen o mal gobierno \\
\hline Comunicaciones & Diálogo, sensibilización \\
\hline Campañas & Compromiso, implicación \\
\hline
\end{tabular}

Fuente: Darnton y Kirk (2011, p. 94).

\section{Metodología}

\section{Objetivos y objetos}

El estudio viene definido por un objetivo general doble:

- Estudiar el discurso sobre CSI transmitido por los medios mencionados.

- Estudiar la concepción de la cooperación y el desarrollo en las redacciones.

El objeto de estudio también es doble. Por una parte, está compuesto por un conjunto de piezas emitidas o publicadas en medios locales o regionales catalanes o en medios estatales que hayan sido elaboradas por las redacciones catalanas de medios estatales. Claro está que tales piezas deben tener relación con la CSI. Por otra parte, el objeto también está compuesto por el contenido de las entrevistas a miembros de las redacciones sobre su concepción de la CSI.

Ahora bien, como los dos objetivos tienen como finalidad conjunta encontrar caminos para mejorar la calidad y la cantidad de la presencia de la CSI en los medios, entonces los objetivos generales se concretan en los siguientes objetivos específicos:

1. Reconstruir la matriz ideológica del discurso de cada medio.

2. Detectar la presencia de fuentes y actores del Sur y del Norte.

3. Identificar los valores y los marcos promovidos por los medios con base en la matriz de las proposiciones extraídas.

4. Identificar eventuales estereotipos sobre el Sur. 
5. Evaluar los obstáculos y las oportunidades para difundir una información favorable a la cooperación y al desarrollo en los medios.

\section{Delimitación del corpus}

El corpus está compuesto por un promedio de diez piezas para cada medio que han sido recogidas tras una selección efectuada por periodistas de los mismos medios analizados y publicadas entre abril de 2012 y marzo de 2013. De esta forma, a petición del equipo investigador, los periodistas contactados enviaron piezas que estimaron representativas de su trabajo, lo cual ha sido tenido en cuenta en el momento de establecer los resultados.

Se ha dispuesto de piezas procedentes de catorce medios, escogidos de forma que combinan una alta audiencia y un representatividad geográfica amplia: dos canales de televisión (TV3 y 8TV), dos estaciones de radio (CatRàdio, RAC1), nueve periódicos (La Vanguardia, El Periódico, El País edición Catalunya, El Punt-Avui, Ara, Regió 7 , El 9 Nou, Diari de Girona, La Mañana y el Diari de Tarragona) y del portal informativo de VilaWeb. En total, 112 piezas de dimensiones variadas entre medianas y grandes, en un sentido relativo a la medida habitual que emplea cada medio.

Las piezas no se han recolectado aleatoriamente ni con un barrido sistemático, sino de acuerdo con el objetivo estratégico del proyecto madre, que es la creación de una red de comunicadores y periodistas. Las piezas analizadas han sido escogidas por una persona de la redacción que, en alguna medida, conoce el campo de la CSI. En ocasiones han sido redactores de base y, en otras, han sido periodistas con alguna responsabilidad en la redacción. Solo se puso como condición que hubiesen sido publicadas en los últimos tres años.

En consecuencia, hemos obtenido una muestra rica en contenido, de piezas no banales que, de entrada, son consideradas positivas por alguien del medio y, por tanto, ya tienen un cierto grado de representatividad sobre lo que se considera una cobertura adecuada de la CSI.

\section{Procedimiento y ficha de análisis de las piezas}

Para analizar las piezas, en primer lugar, se transcribieron y después se diligenció la ficha de análisis que se describe a continuación, dividida en dos partes: una técnica y otra analítica.

Aparte de la identificación técnica, cada pieza se ha sometido a un vaciado a escala proposicional y macroproposicional. Más adelante explicaremos cómo se deducen las proposiciones.

La parte analítica de la ficha que mostramos a continuación esquematiza el procedimiento para las informaciones de televisión que luego fue adaptada para los otros medios. Prácticamente, bastaba con reducir (para las piezas con fotografías o ilustraciones) o eliminar la parte correspondiente a las imágenes (por ejemplo, para informativos de radio). 


\section{Modelo de ficha para televisión. Parte analítica}

\section{Tabla 2. Fuentes}

\begin{tabular}{|l|l|}
\hline & Quién \\
\hline Fuentes & \\
\hline
\end{tabular}

\begin{tabular}{|c|c|c|c|c|c|c|c|}
\hline & $\begin{array}{c}\text { Organizaciones } \\
\text { internacionales } \\
\text { (no ONG) }\end{array}$ & Gubernamentales & $\begin{array}{c}\text { ONG } \\
\text { internacionales }\end{array}$ & $\begin{array}{l}\text { ONG } \\
\text { (local) }\end{array}$ & Beneficiarios & Expertos & $\begin{array}{c}\text { Otros } \\
\text { ciudadanos }\end{array}$ \\
\hline $\begin{array}{l}\text { Número } \\
\text { fuentes } \\
\text { Norte }\end{array}$ & & & & & & & \\
\hline $\begin{array}{l}\text { Número } \\
\text { fuentes } \\
\text { Sur }\end{array}$ & & & & & & & \\
\hline
\end{tabular}

\begin{tabular}{|l|l|}
\hline Actores de cooperación & Quién \\
\hline Del Norte & \\
\hline Del Sur & \\
\hline
\end{tabular}

\begin{tabular}{|c|c|c|}
\hline $\begin{array}{c}\text { Testimonios CSI } \\
\text { Quién }\end{array}$ & Con qué términos o en qué frase aparece & $\begin{array}{c}\text { Positivo, negativo o } \\
\text { neutro }\end{array}$ \\
\hline & & \\
\hline
\end{tabular}

Fuente: elaboración propia.

Valoramos si la presentación del testimonio es positiva, negativa o neutra.

Las elecciones léxicas de los nombres, los adjetivos y los verbos permiten identificar si la carga valorativa con la que se presentan tanto los actores como sus acciones es de uno u otro tipo, eso sí, sin perder de vista el contexto axiológico. Por ejemplo, si un reportaje de la sección de religión de un diario informa que "La escuela X ha donado mil euros para los niños africanos”, no hace falta que haya ninguna valoración explícita para deducir que la acción y el actor están presentados de forma positiva.

Hasta aquí son celdas para cubrir el objetivo 2: detectar la presencia de fuentes y actores del Sur y del Norte.

Tabla 3. Macroproposiciones globales

\begin{tabular}{|l|l|}
\hline Macroproposiciones & \\
\hline- \\
-
\end{tabular}

Fuente: elaboración propia. 
Aunque la tabla de macroproposiciones esté al principio (para facilitar el acceso inmediato del investigador), puesto que contiene un resumen de la pieza, se rellena después de haber completado las tablas siguientes.

Con la recopilación de las macroproposiciones cubrimos una fase (final) del objetivo 1: reconstruir la matriz ideológica del discurso de cada medio.

La primera fase del objetivo 1 consiste en el vaciado de las proposiciones, para lo cual sirve la tabla 4:

Tabla 4. Descripción y extracción

\begin{tabular}{|l|l|l|}
\hline \multicolumn{1}{|c|}{ Texto-audio } & Imágenes-descripción & Proposiciones extraídas \\
\hline [Titular] & & \\
\hline [Destacado 1] & & \\
\hline [Destacado 2] & & \\
\hline [Cuerpo-primer párrafo] & & \\
\hline [Cuerpo-segundo párrafo] & & \\
\hline$\ldots$ & & \\
\hline
\end{tabular}

Fuente: elaboración propia.

La celda [Titular] se puede repetir si hay más elementos de titulación y lo mismo vale para destacados o partes del cuerpo. En la segunda columna, las imágenes se describen sucintamente y, en la tercera, se exponen las proposiciones extraídas tanto si son explícitas como implícitas.

En la tabla 5 se justifican las extracciones de las explícitas y sobre todo de las implícitas. Una fila para cada proposición extraída.

Tabla 5. Explicaciones

\begin{tabular}{|l|l|}
\hline Proposiciones extraídas & Explicación de la extracción-deducción \\
\hline & \\
\hline & \\
\hline & \\
\hline
\end{tabular}

Fuente: elaboración propia.

Las proposiciones son formulaciones claras de las ideas contenidas en el discurso, de preferencia con la estructura sujeto-verbo-predicado. Si la proposición es explícita, basta con copiar o reformular el fragmento localizado. Si la proposición es implícita, tenemos tres mecanismos de significación que la generan: presuposiciones, implicaciones e implicaturas ${ }^{1}$.

1 Respecto a estos conceptos de pragmática semántica, pueden verse Levinson (1983) y Leech (1983). 


\section{DISERTACIONES}

\section{ESTUDIOS}

Anuario electrónico de estudios en Comunicación Social

ISSN: $1856-9536$

Doi: dx.doi.org/10.12804/revistas.urosario.edu.co/disertaciones/a.4914

Volumen 10, Número 1 / Enero-junio 2017

Versión PDF para imprimir desde

http://revistas.urosario.edu.co/index.php/disertaciones

Veamos con un ejemplo cómo funciona la extracción. Imaginemos que encontramos un fragmento que reza: "El Gobierno de Haití no arregla el envío de ayuda a los barrios del norte de Puerto Príncipe".

El texto presupone que: "El Gobierno de Haití existe".

Es una presuposición tanto si el Gobierno arregla el envío de ayuda como si no lo hace.

Esta presuposición tiene valor semántico si está en duda que el Gobierno exista; en caso contrario, no vale la pena considerarla.

Veamos una presuposición más: "La ayuda existe".

Tanto si la envían como si no, el texto presupone que la ayuda existe.

Veamos ahora una implicación: "El envío de la ayuda no funciona bien".

Ahora, una más, derivada de esta: "El Gobierno debe arreglar el envío de ayuda".

El texto no afirma explícitamente que el Gobierno deba arreglar el envío, pero el verbo "arreglar" implica que algo no funciona y si, además, se dice que el gobierno no lo arregla, automáticamente se insta al Gobierno a que lo repare.

Veamos qué es una implicatura antes de deducir una de las posibles. Se entiende por implicatura una proposición derivada de la combinación del significado (explícito o implícito) de un fragmento discursivo con el conocimiento o con creencias extratextuales de una determinada audiencia.

Si entre el público receptor del fragmento que usamos como ejemplo existe la creencia de que un Gobierno que no es efectivo en la gestión de la ayuda que debe dimitir, se deduce que, para ese público, el fragmento identificado también comporta la proposición: "El Gobierno de Haití debe dimitir".

En la tabla 6 se reagrupan las proposiciones, si las hay, en función del marco superficial que evoca su contenido y se explica cómo lo hacen. Así cumplimos el objetivo 3: identificar los valores y los marcos difundidos por los medios con base en la matriz de las proposiciones extraídas.

Tabla 6. Proposiciones del marco asistencial

\begin{tabular}{|l|l|}
\hline & Proposiciones \\
\hline Caridad & \\
\hline Explicación & \\
\hline
\end{tabular}

\begin{tabular}{|l|l|}
\hline & Proposiciones \\
\hline Entidades beneficencia & \\
\hline Explicación & \\
\hline & \\
\hline
\end{tabular}

\begin{tabular}{|l|l|}
\hline & Proposiciones \\
\hline Ayuda & \\
\hline Explicación & \\
\hline
\end{tabular}




\begin{tabular}{|l|l|}
\hline & Proposiciones \\
\hline Desarrollo (con lógica de superioridad) & \\
\hline Explicación & \\
\hline
\end{tabular}

\begin{tabular}{|l|l|}
\hline & Proposiciones \\
\hline Centrada en corrupción o efectividad ayuda & \\
\hline Explicación & \\
\hline
\end{tabular}

\begin{tabular}{|l|l|}
\hline & Proposiciones \\
\hline Centrada en comunicaciones & \\
\hline Explicación & \\
\hline
\end{tabular}

\begin{tabular}{|l|l|}
\hline & Proposiciones \\
\hline Campañas & \\
\hline Explicación \\
\hline
\end{tabular}

Fuente: elaboración propia.

Lo mismo se repite para los marcos superficiales alternativos de justicia y equidad o transformación (tabla 7):

Tabla 7. Marco alternativo

\begin{tabular}{|l|}
\hline Justicia y equidad \\
\hline Movilización social, ONG \\
\hline Partenariado, apoyo mutuo \\
\hline Bienestar, libertad, responsabilidad \\
\hline Buen o mal gobierno \\
\hline Diálogo, sensibilización \\
\hline Compromiso, implicación \\
\hline
\end{tabular}

Fuente: elaboración propia.

Por último, se registran eventuales estereotipos (objetivo 4) (tabla 8):

\section{4}




\begin{tabular}{|l|c|}
\hline Estereotipos & Proposición que los contiene \\
\hline & \\
\hline
\end{tabular}

Fuente: elaboración propia.

A efectos del campo que trabajamos, entendemos que un estereotipo es una generalización de un rasgo o una característica de un cierto número de individuos a todo el grupo étnico o nacional al que pertenecen. La generalización puede ser formulada directamente o inducida por la repetición de la caracterización de miembros particulares del grupo étnico o nacional en cuestión. De estudios precedentes (Giró, Farrera y Carrera, 2014; CNTV, 2010; Fueyo, 2002; Arcas, 2007; Da Cruz, 2003), se ha identificado el siguiente conjunto de estereotipos sobre el Sur:

- Los países del Sur son difíciles de gobernar.

- No conocen la democracia.

- No saben cómo organizarse; son caóticos.

- Hay corrupción por todas partes.

- Ellos son así.

- Su cultura hace que sean como son.

- Son pasivos, no tienen iniciativa, no son emprendedores.

- Es necesario enseñarles.

- Necesitan la ayuda del Norte.

- Sus religiones son primarias.

- Son violentos.

- No respetan a las mujeres.

- Etcétera.

\section{Las entrevistas}

Para el segundo objetivo general (estudiar la concepción de la cooperación y del desarrollo en las redacciones) y para el objetivo específico 5 (evaluar los obstáculos y las oportunidades para una información favorable a la cooperación y al desarrollo en los medios) hemos entrevistado miembros de los medios de comunicación que han seguido de forma flexible el guion que se encuentra en el anexo 1.

Como se ha apuntado, se entrevistó a los periodistas que han elaborado piezas analizadas y también, en algunos casos, a responsables de la redacción, para un total de trece personas: una redactora de TV3, un jefe de RAC1, un subdirector de La Vanguardia, una redactora de El Periódico, un periodista de El País, dos jefes de sección del diario ARA, un jefe del Diari de Tarragona, dos redactoras del Diari de Girona, un jefe del diario El 9 Nou, una redactora del diario El Punt-Avui y el director del portal Vilaweb. 


\section{Resultados}

A continuación se presentan los resultados conjuntos, con el fin de ofrecer una visión general. Descartamos exponer los resultados de cada medio, pues resultaría una narración repetitiva y tediosa.

\section{Posición destacada y positiva}

De las 112 piezas, 61 están en posiciones preeminentes en sus medios (por ejemplo, abren página) y 70 son grandes (más de media página en medios escritos, por ejemplo), o sea que cuando la información sobre cooperación aparece, no lo hace en un rincón.

La inmensa mayoría (102) ofrece una visión positiva de la cooperación sea cual sea el enfoque con el que se aborda. Solo cuatro la dan negativa y seis, neutra. No sorprende que tantas piezas muestren una visión positiva, ya que han sido elegidas por los periodistas, mas el resultado indica cuál es el tono preferido con el que se asume.

\section{Dominio de la política: los recortes en cooperación}

El tema principal en el período estudiado fue el de los recortes en las Administraciones catalana y española que afectó a subvenciones a proyectos de todo tipo, incluidos los gestionados por ONG. No son la mayoría absoluta, pero sí el asunto más destacado (gráfico 1 ).

\section{Gráfico 1. Tema principal}

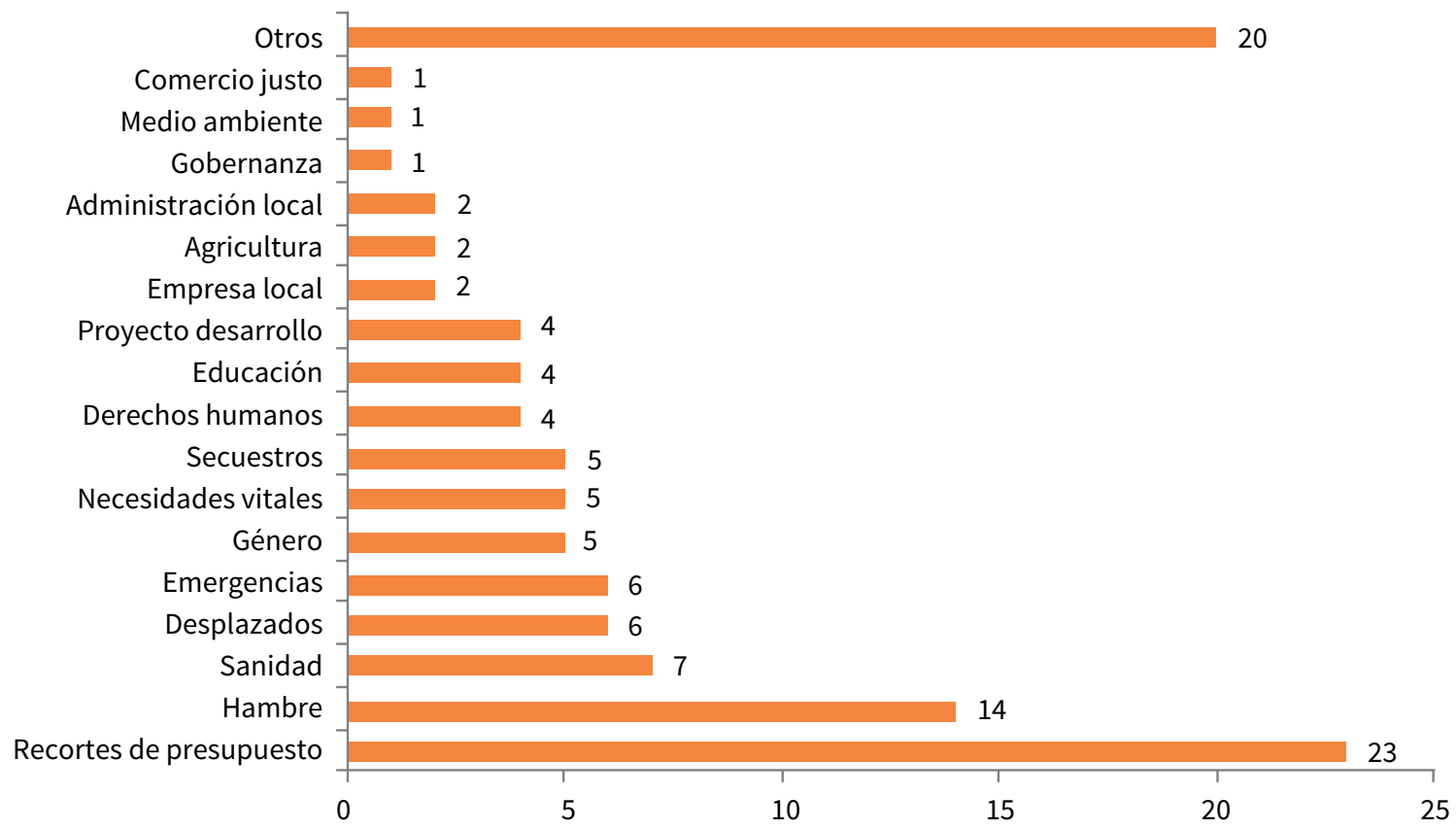

Fuente: elaboración propia. 


\section{Noticiabilidad}

Si prestamos atención al factor de noticiabilidad de las piezas, los recortes siguen en un lugar destacado (23), pero la sensibilización o la divulgación de proyectos de cooperación ofrece suficientes atractivos para ganarse un lugar en la agenda (24). El gráfico 2 muestra dónde ha estado el gancho informativo.

El factor de noticiabilidad se determina a partir del titular y de la respuesta básica a la pregunta: "QQué novedad aporta esta información?".

Gráfico 2. Noticiabilidad. Publicado a raíz de...

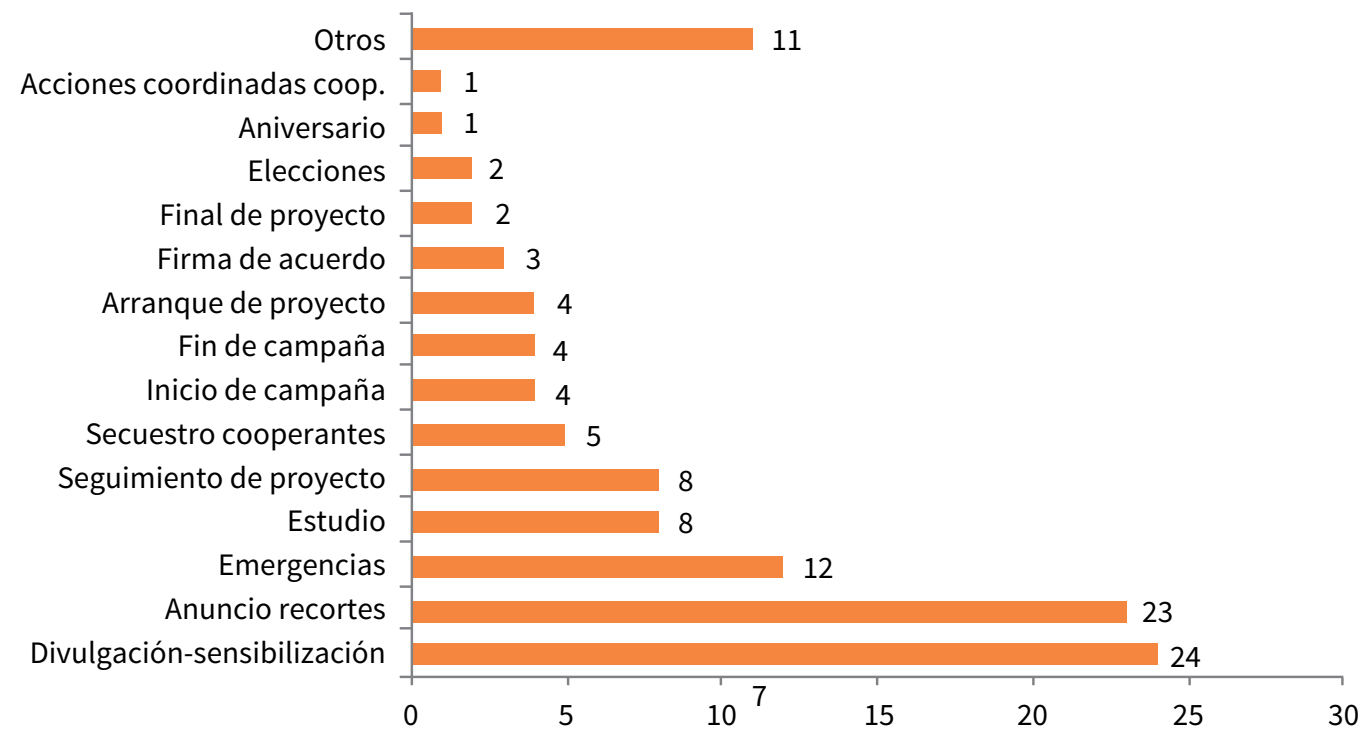

Fuente: elaboración propia.

En los medios locales, la divulgación de proyectos ligados a su zona, en donde los protagonistas son personas u organizaciones del lugar que se desplazan al Sur o desempeña alguna actividad a favor del Sur, consigue más espacio que en los medios generalistas. El criterio de proximidad vive su esplendor. Sin embargo, las contrapartes del Sur no suelen aparecer como fuentes o expertos, ya que las piezas periodísticas han sido elaboradas en la misma localidad catalana con material (fotografías e informes) traído por los cooperantes.

\section{Las voces presentes}

La voz de los actores del Sur solo aparece si el periodista ha viajado hasta el emplazamiento del proyecto, lo cual sucede si ha habido una emergencia o bien si alguien (Gobierno u ONG) financia el viaje. El gráfico 3 muestra la poca presencia de tipos de fuentes o testimonios del Sur y su eventual aparición combinada. 


\section{Gráfico 3. Fuentes de información. Presencia de ONG y de fuentes locales, solas o combinadas}

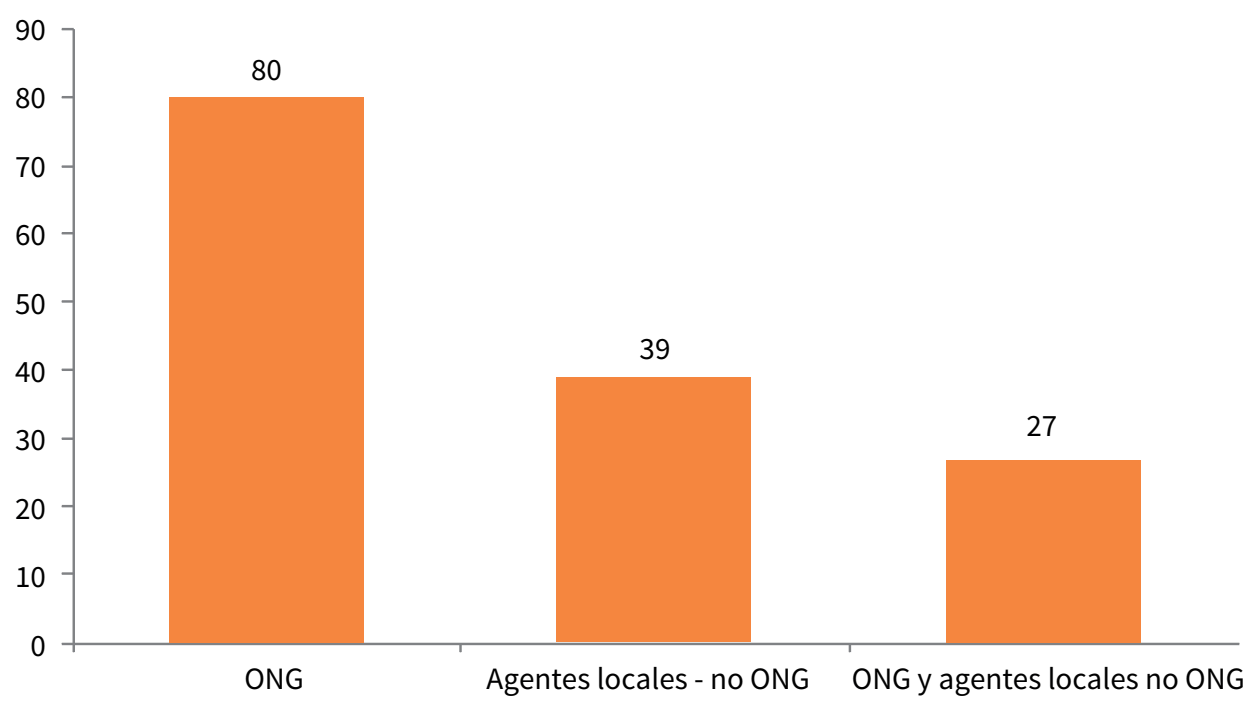

Fuente: elaboración propia.

\section{Los valores difundidos}

Con respecto a los valores que subyacen en los marcos superficiales, el más promovido es "ayuda" con algunas variaciones: "ayuda al tercer mundo", "ayuda humanitaria”, "ayuda sanitaria” y "ayuda educativa”. También están presentes las versiones simples de "donaciones" o "donaciones de empresas".

El segundo grupo de valores en importancia cuantitativa está integrado por "derechos, justicia, solidaridad", "mujeres" (relacionado con empoderamiento y cambio del modelo de sociedad machista) y "cooperación (entendida como intercambio real entre dos partes, entre iguales) y autodesarrollo".

Con la misma relevancia se encuentra el grupo de valores compuesto por "comercio", "efectividad de la ayuda", "responsabilidad política" y también "ONG" (como un valor en sí mismas). Cuando aparecen, los valores "responsabilidad política” y “ONG” están asociados con el marco hegemónico. La "responsabilidad política” se refiere a la de los Gobiernos español y catalán por incumplir los compromisos de financiación de la "ayuda" y el valor "ONG" aflora porque los recortes generan una respuesta defensiva de las propias ONG, a favor de su supervivencia como entidades del tejido social del Norte y por las pérdidas de puestos de trabajo que comportan los recortes. Aunque este no es el único enfoque de las protestas y de las informaciones, es el predominante.

Hay piezas a favor de la independencia de las ONG con respecto a las subvenciones públicas que sugieren nuevas vías para ganar asociados. Su posición es implícita, pues se transmite al recoger la palabra de expertos que, además, emplazan a las ONG a actuar como agentes de presión política.

El valor "mujeres" aparece, por ejemplo, en una pieza que menciona su empoderamiento y en otra referida a la lucha contra los ataques machistas. En el gráfico 4 se aprecia que los valores vinculados al marco hegemónico sobre la cooperación vertical Norte-Sur (73) superan el número de piezas sobre derechos, justicia y autodesarrollo (47). Contamos aquí el valor preponderante de la pieza y no todos los valores presentes en cada una de ellas. 


\section{Gráfico 4. Valores}

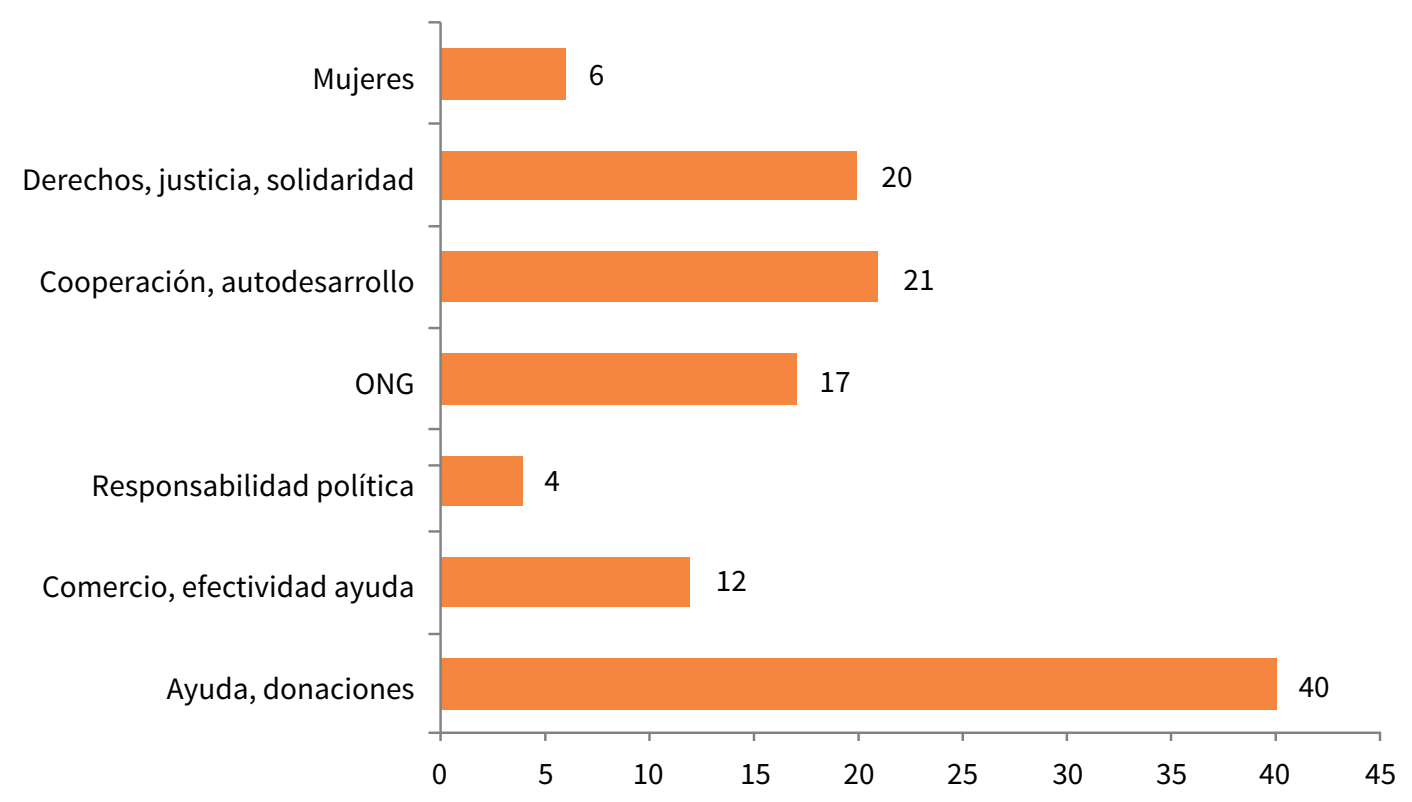

Fuente: elaboración propia.

Puesto que la mayoría de piezas tiene una extensión considerable, no sorprende que en algunas convivan proposiciones del marco tradicional con otras del marco transformador. En las fichas se prevé la posibilidad de que ambos tipos de marcos estén presentes y, por lo tanto, que se pueda dejar constancia en la ficha de que eso ocurre, o sea, se ha podido evaluar si una pieza promovía un marco, otro, ambos o ninguno de ellos.

\section{Discurso híbrido, marcos copresentes}

El marco predominante es "caridad-ayuda" (73 piezas), pero está acompañado en 26 piezas por el marco "cooperación-justicia-transformación" (que antes llamamos justicia y equidad). El marco alternativo se promueve en solitario en 25 piezas, que es equiparable al número de piezas (solo hay una de diferencia) en las que aparece de la mano del marco tradicional. De aquí que podamos hablar de modos híbridos de discurso sobre la cooperación (gráfico 5). 


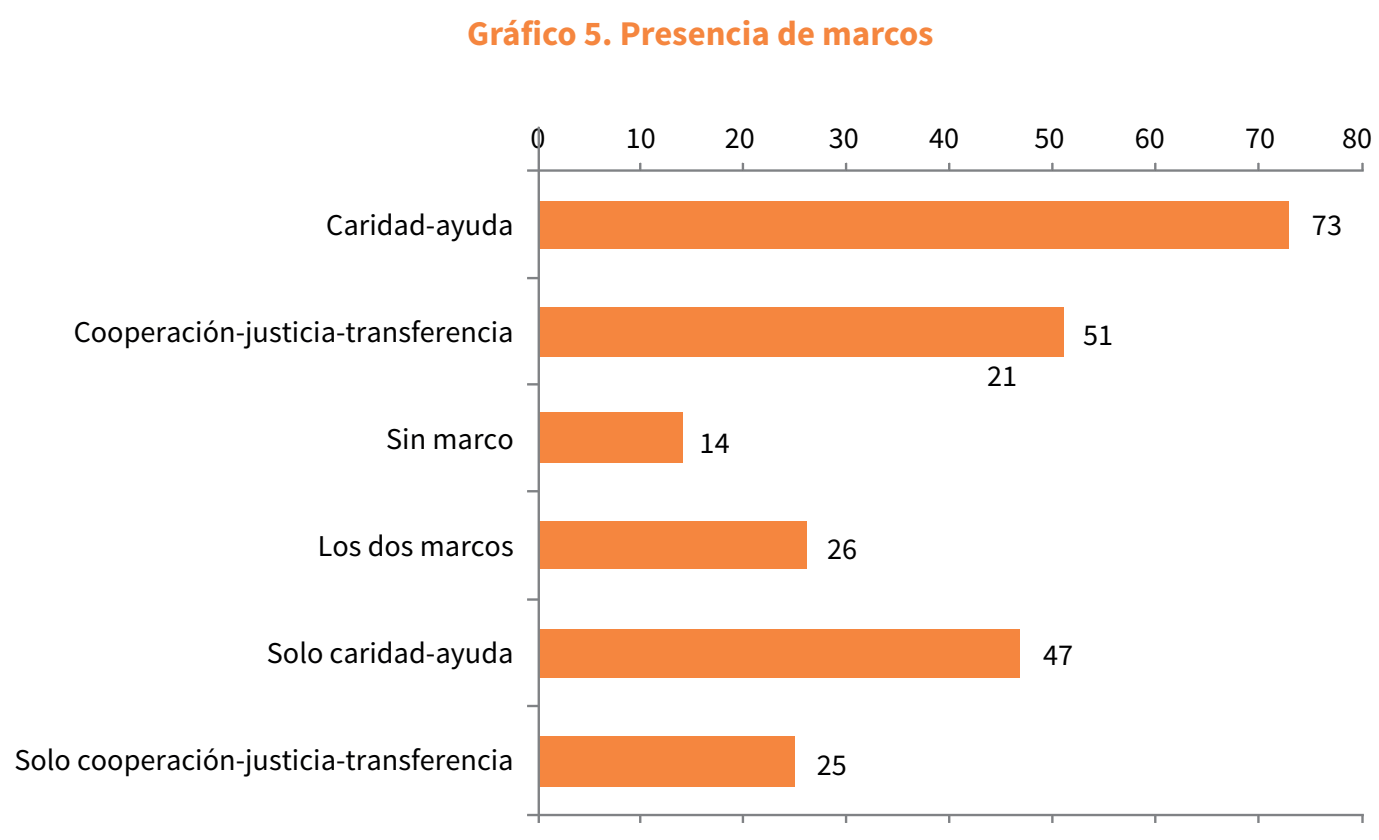

Fuente: elaboración propia.

La aparición simultánea de ambos marcos es coherente con una concepción que no implica que uno y otro marco son antagónicos, sino que estima que las intervenciones asistenciales se hacen cuando son necesarias por su urgencia, pero se pueden y deben -o deberían - entenderse como intervenciones puntuales que forman parte de una estrategia global que persigue la justicia, la equidad y las transformaciones sociales. Una estrategia que llega hasta el empoderamiento de la gente del Norte y del Sur para ir tomando el futuro con sus propias manos.

Algunas piezas no ofrecen ningún marco, porque solo se refieren a la cooperación sin mayor detalle. He aquí ejemplos de proposiciones recogidas del marco "caridad-ayuda":

- "Avances como los registrados en alimentación se verán truncados por culpa de los recortes" (El PuntAvui, 6 de julio de 2011).

- "Hay jóvenes que aprovechan el verano para realizar trabajos solidarios" (Diari de Tarragona, 8 de agosto de 2011).

- "Los proyectos responden a las necesidades justificadas en espacios de escasez por todo el mundo" (Diari de Tarragona, 23 de abril de 2008).

- "Los ciudadanos comprometidos del norte recogen fondos para jóvenes desfavorecidos de República Dominicana" (El 9 Nou, 26 de febrero de 2010).

- "La aplicación efectiva del tratamiento de la enfermedad dependerá de los donantes de fondos del Norte" (Cat Ràdio, 23 de marzo de 2013). 
- "La incapacidad y corrupción del gobierno haitiano deja desamparada a la población de manera que las acciones de cooperación internacional son positivas, justificadas y totalmente necesarias o imprescindibles para la supervivencia de la población haitiana enferma" (TV3, 16 de noviembre de 2011).

Acá presentamos ejemplos de proposiciones con una orientación de "justicia-equidad-transformación":

- "Las empresas farmacéuticas no están interesadas en los problemas de África” (La Vanguardia, 27 de enero de 2013).

- "Hace falta una reforma agraria para tener seguridad alimentaria" (Cat Ràdio, 10 de mayo de 2013).

- "El comercio es justo si hay un precio justo, condiciones laborales dignas, es sostenible, y hay un retorno del beneficio a la comunidad". (TV3, 18 de junio de 2010).

- "Las poblaciones receptoras sufren explotación, marginación e injusticia” (Diari de Tarragona, 23 de julio de 2006).

- "Las ONG del sur tienen métodos e ideas concebidas para encarar problemas específicos de su país que han demostrado que funcionan y que tienen efectos de desarrollo eficaces a largo plazo tanto a nivel individual como comunitario" (TV3, 20 de junio de 2011).

\section{Estereotipos}

En relación con los estereotipos sobre los ciudadanos del Sur, se ha detectado que los hay en un $16 \%$ de las piezas. Los tópicos son de moderada intensidad y, aunque no son generalizaciones flagrantes, su reiteración proyecta el estereotipo sobre el conjunto del país o del grupo étnico.

La evocación de términos como la "pobreza" o la "extrema pobreza" y la "pasividad" de la población serían comprensibles en la información sobre emergencias, pero el goteo mantenido de referencias a los tres términos para una población específica - y a veces con la mención explícita de su nacionalidad- abre la puerta a la generalización y, por tanto, a la creación o al refuerzo del estereotipo preexistente entre la audiencia.

Lo mismo ocurre si se habla de la presencia de la "corrupción" o de la "incapacidad de gobernarse" o de "incapacidad de mantener una Administración pública”, en referencia a ciertos grupos humanos o nacionalidades. Las incapacidades también se relacionan con lo que los medios describen como "supersticiones" de una comunidad que incapacitarían a los gobernantes o a los ciudadanos para tomar decisiones como lo habría hecho un actor racional del Norte. Los estereotipos, al fin y al cabo neocoloniales, son una concreción más del marco de la ayuda y la caridad; un esquema asistencialista.

\section{Qué dicen las entrevistas a periodistas}

El resultado global de las entrevistas a periodistas de distintos medios se puede condensar en los siguientes puntos.

1. Los modelos de cooperación no se perciben como alternativos, sino como un conjunto de acciones o mecanismos compatibles que parten de la ayuda en las emergencias y se van ampliando progresivamente en el siguiente orden:

- Actuaciones de emergencia.

- Atención a las necesidades básicas de la población (incluye los casos de emergencias). 


\section{DISERTACIONES}

ESTUDIOS

Anuario electrónico de estudios en Comunicación Social

ISSN: 1856-9536

Doi: dx.doi.org/10.12804/revistas.urosario.edu.co/disertaciones/a.4914

Volumen 10, Número 1/ Enero-junio 2017

Versión PDF para imprimir desde

http://revistas.urosario.edu.co/index.php/disertaciones

- Lucha o actuaciones a favor de los derechos económicos, sociales y políticos (abarca la atención a las necesidades básicas).

- Lucha o construcción de instrumentos e instituciones que sirvan para conseguir y consolidar los derechos antes mencionados (comprende la satisfacción de los derechos).

- Empoderamiento de los actores para conseguir la justicia local y global (cubre el punto anterior).

2. La cooperación ideal es la que promueve el desarrollo sostenible y cambios estructurales. Debe tener objetivos claros, ser eficaz y profesional. Hay que evitar el apoltronamiento de los cooperantes.

3. Las campañas de las ONG suelen ser clásicas y estereotipadas. Algunas presentan la bondad de la cooperación con base en el beneficio que aportaría al Norte, con lo cual ser refuerza la ideología del "nosotros-primero". Las mejores campañas periodísticas son las de sensibilización, porque aportan datos, contexto global e historias humanas. Ahora, las redes sociales son de gran ayuda para ellas.

4. La noticiabilidad la dan los conflictos, la novedad, lo urgente, la actualidad, los próximos (ya sea en sentido geográfico, emotivo o ideológico). Las informaciones sobre cooperación no tienen gancho si son tangenciales, intemporales, sin imágenes, esporádicas o sus contactos son inaccesibles. Para asegurar que los proyectos se difundan o se publiquen: a) el periodista debería desplazarse al territorio; b) debería haber testimonios para ilustrar los datos (los datos fríos valen menos), y c) las historias deberían ser originales, singulares, con alguna gracia. Así, el relato estaría cargado de realidad palpable, buena, en términos periodísticos.

5. En la comunicación entre periodistas y ONG funcionan bien los gabinetes de prensa y los tándems ONG-medio. Haría falta que las ONG pequeñas tuvieran una central de venta - difusión- de proyectos, esto facilitaría el trabajo de los reporteros. Los informes que hacen las ONG deben ser más trabajados para hacerlos atractivos para los medios y, en particular, adaptados para los medios locales.

\section{Conclusiones: la complejidad en la determinación del marco interpretativo}

Si tenemos en cuenta los resultados que ya hemos presentado y los combinamos con el resultado de las entrevistas, estamos en condiciones de responder a la pregunta ¿por qué una pieza promueve un marco u otro? O, en el caso de que coexistan dos, ¿qué hace que uno tenga más peso que el otro? Apreciamos que existen distintas variables que, combinadas de una forma compleja, explican cuál es el marco interpretativo que se desprende de una pieza determinada. En la demostración de la función que presentamos, además de los razonamientos que la sostienen, se aportan nuevas concreciones de los resultados, que fundamentan o ilustran las deducciones.

El resultado se puede expresar con la siguiente formulación:

\section{Marco = F (acción, actores-fuente, cultura cooperativa, medio, programa-sección, periodista)}

El marco interpretativo resultante es una función (F) de las siguientes variables: 1) la acción cooperativa en sí misma; 2) el discurso de los actores que operen como fuente de información; 3) la cultura social sobre cooperación de la audiencia del medio; 4) la ideología y los recursos del medio; 5) el espacio en el que se publica o emite la 


\section{DISERTACIONES}

ESTUDIOS

Anuario electrónico de estudios en Comunicación Social

ISSN: 1856-9536

Doi: dx.doi.org/10.12804/revistas.urosario.edu.co/disertaciones/a.4914

Volumen 10, Número 1 / Enero-junio 2017

Versión PDF para imprimir desde

http://revistas.urosario.edu.co/index.php/disertaciones

pieza, su sección en el periódico o su programa en un medio audiovisual, y 6) la ideología y la posición jerárquica del periodista. Veamos cómo opera cada variable.

\section{a) Acción}

El tipo de hecho noticiable o de acción de cooperación (ya sea asistencialista o transformadora) empuja y orienta el enfoque periodístico. Si la acción es transformadora, es probable que el discurso también lo sea, pero si es caritativa, difícilmente la información transmitirá un marco distinto, aunque existe la posibilidad de que así sea, como veremos más adelante. Lo constatan, por ejemplo, diversas entrevistas que ponen de manifiesto que la noticiabilidad máxima viene dada por las emergencias humanitarias registradas después de catástrofes o conflictos armados. Una parte de la cobertura de Haití fue paradigmáticamente asistencialista. Además, cuanto menor sea la pieza informativa, menos espacio hay para el contexto o la perspectiva, porque los datos del momento tienen prioridad.

\section{b) Discurso del actor-fuente}

El marco interpretativo explicitado por los actores o por expertos en sus declaraciones impregna el discurso periodístico y tiene, por tanto, una alta posibilidad de determinar el marco de conjunto de la información, siempre que sea capaz de dar coherencia semántica a la pieza.

De entrada, el periodista transmite la visión de las fuentes, por el hecho de reproducir sus palabras. Claro está que también puede ser crítico con las fuentes -explícita o implícitamente- $y$, aunque las reproduzca, las puede desacreditar o marginar en el conjunto de la pieza, de modo que el marco resultante sea la antítesis del marco que ha expuesto la fuente. Sin embargo, los casos estudiados muestran que no suele ser así.

En diversas piezas en las que se habla de situaciones de emergencia alimentaria o sanitaria, tanto en TV3 como en La Vanguardia, aparecen actores del Norte que sitúan las acciones - por ejemplo, donaciones para adquirir material médico- como parte de un plan general que devuelve el control y la planificación del desarrollo a las contrapartes locales y, por ende, dentro del marco de autodesarrollo, justicia y transformación.

También hay piezas en las que los actores locales, por el simple hecho de aparecer como actores con capacidad para controlar las acciones de cooperación, evidencian el empoderamiento de los mismos actores

Las piezas no suelen ir en dirección contraria a la de los actores-fuente porque, por un lado, la cooperación es considerada positiva - cualquiera que sea su forma-; por lo tanto, sería muy sorprendente que la pieza adoptara una posición negativa hacia quien presenta la acción. Por otro lado, ir en sentido contrario requeriría para el periodista un tiempo adicional que muy pocas veces tiene a su alcance y, si optase por contradecir a la fuente, su decisión comportaría quemarla, lo cual es un lujo muy caro en periodismo.

En definitiva, los actores-fuente y también los expertos influyen en el marco final, aunque no se puedan considerar determinantes.

\section{c) Cultura social sobre cooperación}

Si una sociedad está acostumbrada a campañas como los telemaratones para recolectar dinero para emergencias o para investigar sobre enfermedades poco atendidas en la sanidad pública, no se escapa a la percepción del 


\section{DISERTACIONES}

ESTUDIOS

Anuario electrónico de estudios en Comunicación Social

ISSN: $1856-9536$

Doi: dx.doi.org/10.12804/revistas.urosario.edu.co/disertaciones/a.4914

Volumen 10, Número 1 / Enero-junio 2017

Versión PDF para imprimir desde

http://revistas.urosario.edu.co/index.php/disertaciones

periodista que partimos de una sociedad en la cual la idea hegemónica de la solidaridad y, por extensión, la cooperación son de naturaleza caritativa y asistencial.

Si ese es el caso, como ocurre en el contexto español y catalán, a una parte del público le costará entender el sentido de actuaciones no dadivosas, sino transformadoras. Cuanto más de masas sea el medio de comunicación, más presente está en su planteamiento que el ciudadano medio piensa en términos caritativos y, para no perder audiencia o para aumentarla, primero, tenderá a privilegiar acciones comprensibles que encajen con el imaginario del público y, en segundo lugar, aunque sean acciones transformadoras, apuntará a presentarlas con un prisma asistencial o a enfatizar sus aspectos asistenciales.

La entrevista a la periodista de El Periódico, un diario popular de alta circulación, evidencia que el espacio social al que va dirigido demanda asuntos sin complicación y con fotografías abundantes. Lo dicho no impide que el diario también se ocupe del campo de las injusticias y los derechos humanos con un enfoque transformador, en especial en defensa de los derechos de las mujeres.

\section{d) Ideología y recursos del medio}

El medio como variable de la ecuación presenta dos variables: la ideología y los recursos.

La posición ideológica del medio - declarada o no- es un factor de fondo que influye a largo plazo en los objetivos informativos de la redacción y afecta al tratamiento de todos los temas, incluidos los relacionados con la agenda internacional y con la cooperación. Aunque su influencia no es absoluta hasta el último rincón del discurso de los medios, si un medio es conservador, tiende al enfoque caritativo.

En otro terreno, si los recursos periodísticos son escasos, no habrá forma de contrastar ni la fuente-actor ni verificar la acción misma, lo cual comporta que la información sea superficial y reproduzca el marco propio de la acción o el de la fuente, si es que aparece.

De vuelta a la ideología del medio, se constata que la posición crítica con respecto a los poderes conlleva una legitimación de la cooperación de forma indistinta. Con los recortes presupuestarios que dejaron en la estacada a un buen número de proyectos, las acciones de protesta contra el Gobierno central o el catalán fueron cubiertas favorablemente por parte del discurso periodístico y, de rebote, con simpatía por la cooperación que se había visto afectada, fuese la que fuese, caritativa o transformadora.

Aun es pertinente una precisión más sobre la ideología de los medios. Los medios de ciudades pequeñas -Diari de Tarragona, Diari de Girona, El 9 Nou - consideran positivo cualquier proyecto cuya idea nazca en su territorio o que tenga un ligamen especial con él. Así, por ejemplo, el Diari de Tarragona, dio tanto una visión positiva de un proyecto transformador liderado por un equipo de la universidad de Tarragona como a una recolecta de dinero para construir una iglesia en Honduras, promovida por un obispo originario de la misma ciudad.

\section{e) Programa o sección}

Dentro de un mismo medio hay programas o secciones que, de partida, tienen planteamientos proclives a uno u otro marco, con relativa independencia de la orientación general del medio. Por ejemplo, dentro de un laxo criterio de actualidad, el programa Latituds, de TV3, se centra en la sensibilización y la divulgación; beneficiado por su duración (casi treinta minutos), se permite contextualizar y desplegar argumentos de fondo capaces de 
enfocar actuaciones asistenciales como partes de una lógica más amplia de transformación y justicia global, tanto mediante el discurso como por medio de la presencia y el testimonio de actores del Sur.

Dentro de la polifonía habitual en los medios, hay programas o secciones que tienen definiciones ideológicas diferentes de la línea del medio, ya sea porque sirven para captar nuevos sectores de público, como porque se emiten fuera del horario estelar, con lo cual disfrutan de un mayor margen de maniobra ideológico.

En los diarios, las secciones Internacional o Sociedad también tienen mayor margen de maniobra ideológico que las de Política. En esa medida, en las primeras hay más posibilidades de aparición para los enfoques en ruptura con la tradición. Hacerlo o no puede ser una decisión del periodista de base. Así se deduce también de la entrevista al subdirector de La Vanguardia, en la que aconseja a las ONG que no busquen influir en los periódicos por arriba -mediante los altos cargos-, sino con una buena relación con los periodistas de base, que quienes presionan para sacar adelante los temas.

\section{f) Periodista}

En el momento de elaborar una pieza, el equipo periodístico (en ocasiones, de una sola persona) tiene en sus manos un cierto margen de maniobra nada desdeñable para decidir el enfoque, el marco. En esa decisión inciden tres variables.

Por un lado, el enfoque dependerá de la concepción que el periodista tenga sobre la cooperación. Por otro lado, puede estar en sus manos escoger las acciones sobre las que escribe o las fuentes que usa para enmarcarlas. En tercer lugar, cuanto más arriba esté en la jerarquía del medio, más podrá aprovechar la flexibilidad ideológica que la mayoría de medios tiene para encajar discursos con perspectivas diferentes a la de la línea editorial.

Diversos reportajes en el diario ARA lo demuestran. Sin desplazarse al lugar en donde se desarrolla el proyecto, sino con el material facilitado por ONG, la reportera encuentra documentación adicional y fuentes adecuadas para hacer de cada pieza un motor de transformación.

En breve, si la periodista conoce la complejidad de los factores que determinan la orientación de una pieza y su articulación, tendrá una considerable capacidad para abrir grietas dentro de los medios y la conciencia pública a favor de una cooperación y solidaridad internacionales que sean transformadoras. El reto consiste en saber operar las variables de la ecuación para hacerla virtuosa. Periodistas, comunicadores y ONG quedan interpelados.

\section{Referencias}

1. Albó, X. (2011). Suma qamaña: convivir bien. ¿Cómo medirlo? En I. Farah y L. Vasapollo (coords.), Vivir bien: ¿Paradigma no capitalista? (pp. 133-144). La Paz: Cides-UMSA.

2. Arcas, I. (ed.). (2007). Medios de comunicación y organizaciones humanitarias en la respuesta a las crisis. Madrid: Instituto de Estudios sobre Conflictos y Acción Humanitaria.

3. CNTV. (2014). Cobertura televisiva del terremoto. La catástrofe vista a través de la pantalla, la audiencia y la industria. Santiago de Chile: Autor.

4. Da Cruz, J. (2003). Ecología social de los desastres. Montevideo: Editorial de Claes y D3E. 


\section{DISERTACIONES}

ESTUDIOS

5. Darnton, A. y Kirk, Martin. (2011). Finding Frames: New Ways to Engage the UK Public in Global Poverty. Londres: Oxfam, UK Aid.

6. Fueyo, A. (2002). De exóticos paraísos y miseria diversas. Publicidad y (re)construcción del imaginario colectivo sobre el Sur. Barcelona: Icaria.

7. Fowler, R. (1991). Language in the News: Discourse and Ideology in the Press. Londres: Routledge.

8. Giri, A. (2005). Reflections and Mobilizations. Dialogues with movements and voluntary Organizations. Nueva Delhi: Sage.

9. Giró, X., Farrera, L. y Carrera, M. (2014). Análisis de la cobertura en dos televisiones públicas de la catástrofe humanitaria de Haití (12 de enero de 2010). Quaderns del CAC, XVII(40), 57-69.

10. Goffman, E. (1974). Frame Analysis: An Essay on the Organization of Experience. Boston: Northeastern University Press.

11. Hall, S. (1996). The Problem of Ideology: Marxism without Guarantees. En D. Morley y K. H. Chen (eds.), Critical Dialogues in Cultural Studies (pp. 24-45). Londres: Routledge.

12. Jäger, S. (1999). Kritische Diskursanalyse. Eine Einführung. Duisburg: DISS.

13. Lakoff, G. (2004). Don't Think of an Elephant: Know Your Values and Frame the Debate. White River Junction: Chelsea Green Pub. Co.

14. Leech, G. (1983). Principles of Pragmatics. Londres: Longman.

15. Levinson, S. (1983). Pragmatics. Cambridge: Cambridge University Press.

16. Saéz, C. y Barranquero, A. (2014). Communication from Good Living. Latin American Critical Epistemologies towards a Biocentric Turn in Communication for Social Change. Manuscrito inédito.

17. Sen, A. (1999). Development as Freedom. Oxford: Oxford University Press.

18. Van Dijk, T. (1996a). Opiniones e ideologías en la prensa. Voces y culturas (10), 9-50.

19. Van Dijk, T. (1996b). Racism and Ideology. Tenerife: RCEI Ediciones, Universidad de la Laguna.

20. Van Dijk, T. (1997). Racismo y análisis crítico de los medios. Barcelona: Paidós.

21. Van Dijk, T. (1977). Texto y contexto. Madrid: Cátedra.

22. Van Dijk, T. (1998). Ideology: A Multidisciplinary Approach. Londres: Sage.

23. Van Dijk, T. (2001). "Multidisciplinary CDA: A Plea for Diversity”. En Wodak y Meyer (2001). (pp. 95-120).

24. Van Dijk, T. (2009). Discurso y poder. Barcelona: Gedisa.

25. Wittgenstein, L. (1984). Philosophische Untersuchungungen. Barcelona: Laia.

26. Wodak, R. y Meyer, M. (eds.). (2001). Methods of Critical Discourse Analysis. Londres: Sage. 


\section{Anexo 1. Guion de las entrevistas a miembros de las redacciones}

Sobre especialización:

- ¿Hay alguien en la redacción especializado o encargado de asuntos relacionados con la cooperación internacional y de los países en desarrollo?

- ¿Has recibido alguna formación especializada? ¿Cómo te informas o cómo te llega la información sobre cooperación?

Sobre cooperación:

- ¿Conoces proyectos de cooperación? ¿En qué consisten? ¿Quién los lleva a cabo? ¿Quién los financia?

- ¿Los encuentras adecuados? ¿Tienen carencias?

- ¿Has cubierto emergencias? ¿Cómo valoras lo que se ha hecho?

- ¿ ¿Has visitado proyectos de cooperación? ¿De ONG? ¿Gubernamentales? ¿Quién pagó el viaje?

- ¿Qué te parecen las campañas de las ONG?

- ¿Cuál sería el ideal de la cooperación? ¿Qué objetivos debería tener?

- ¿Qué criterios usarías para considerar que una sociedad está desarrollada?

- En tu opinión, ¿cuáles son los obstáculos para el desarrollo?

- ¿Qué piensas sobre la propuesta de abandonar la cooperación internacional y dejar tranquilos a los receptores y a las contrapartes?

Sobre noticiabilidad:

- ¿Crees que tu medio dedica pocos, suficientes o demasiados recursos a la cobertura de la cooperación? ¿Por qué?

- ¿Qué criterios utilizas para decidir si una información sobre cooperación se publica o no? ¿Qué le pides para que sea apta para publicarse o emitirse?

- ¿Has hecho coberturas directamente relacionadas con la cooperación? ¿Qué te parecieron? ¿Qué interés periodístico tenían?

- ¿Cómo organizarías la cobertura de proyectos de cooperación de las ONG?

- ¿Sería diferente de la cobertura de la cooperación oficial?

- ¿Qué fuentes utilizas en relación con la cooperación internacional? ¿Usas la Federación de ONG? ¿Pequeñas ONG? ¿Grandes? ¿ONG de emergencias? ¿De desarrollo? ¿Utilizas sus campañas para informarte? ¿Qué otras fuentes tienes?

Sobre la relación con ONG:

- ¿Qué te parece el trabajo de comunicación de las ONG?

- Las ONG a menudo se quejan de que no salen en los medios. ¿Qué es lo que no entienden del funcionamiento de los medios?

- ¿Cómo es tu relación profesional -si es que tienes alguna-con las ONG? 